\title{
Endoscopic Management of Nasal Myiasis: A 10 Years Experience
}

\author{
Rupender K Ranga, SPS Yadav, Anuj Goyal, Arpit Agrawal
}

\begin{abstract}
Background: The present study was undertaken to compare the efficacy of endoscopic removal with conventional techniques in nasal myiasis patients.
\end{abstract}

Materials and methods: O ut of 144, 72 nasal myiasis patients treated using Hopkins rigid nasal endoscope and visible caudal end of maggots was grasped with Blakesley forceps and removed during endoscopy. R ests were identified from crawling movements or the visible caudal end was buried in necrotic material. Complete clearance of cavernous cavity of maggots in affected nasal cavity from anterior nares to choanae was done and same was repeated on other side if needed.

Results: The mean age in two groups was 57.5 years (range 40-60) in nasal myiasis patients whereas there were $20 \%$ males and $80 \%$ females. Mean duration of nasal symptom in both groups was 2 days. Endoscopically mean 120 maggots (range: 90-160) were removed in first sitting as compared to conventional technique where mean of 80 (range: $40-90$ ) were achieved. The mean duration of endoscopic treatment was 2 days whereas in control group it was 5 days. The difference was statistically significant $(p<0.001)$.

Conclusion: Nasal endoscopic procedure is superior to the manual extraction method for removal of maggots. The larvae located in deep and inaccessible areas can be identified and removed easily. The disease was controlled in shorter time and in fewer sittings. Further the quick and complete eradication of myiasis ensures less damage to the intranasal tissues.

Keywords: Maggots, Parasitic infestation of nose, Endoscopic approach to nasal myiasis.

How to cite this article: Ranga RK, Yadav SPS, Goyal A, Agrawal A. Endoscopic Management of Nasal Myiasis: A 10 years Experience. Clin Rhinol An Int J 2013;6(1):58-60.

\section{Source of support: Nil}

Conflict of interest: None declared

\section{INTRODUCTION}

Nasal myiasis, a common entity in tropical counties, is an opportunistic parasitic infestation of human as well as animals caused by house fly larvae (maggots). This can be classified as accidental, facultative (opportunistic) or obligate. ${ }^{1}$ There are many factors responsible for myiasis like low socioeconomic status, immunocompromised state, mental retardation, sinonasal diseases and unhygienic living conditions. The misery is generally associated with trauma, wounds and erosive or ulcerative lesions of skin and mucosa. ${ }^{2}$

$\mathrm{N}$ asal myiasis is considered accidental nasal infestation. $M$ any species of dipterous flies among the genera Chrysomya have been reported to be the most important obligatory myiasis producers among human and animals. ${ }^{3}$
Severity of myiasis depends on location of infestation, lesions and tissue inflammation. The maggots cause extensive necrosis, sloughing and destruction of intranasal tissue and reach to deep and inaccessible areas of the nose and paranasal sinuses. In such a situation removal of maggots is difficult by manual extraction and several sittings are required. To overcome this problem nasal endoscope is being used for removal of maggots under direct vision. The maggots located in deep and inaccessible areas can be approached more easily by endoscopic procedure. The disease is controlled in shorter periods of time and in few sittings, quick and complete eradication of myiasis is possible before the maggots cause irreparable damage to the intranasal tissues. ${ }^{4}$ The study was conducted in nasal myiasis patients to compare the efficacy of endoscopic with conventional removal techniques.

\section{MATERIALS AND METHODS}

The present prospective study was conducted in 144 consecutive patients of either sex in age group of 40 to 60 years suffering from nasal myiasis during 2001 to 2011 in months of A ugust to October. The patients with nasal myiasis presented with nasal bleeding, itching, pain in nose, headache and foul smell. There was history of habitual sleeping in streets in most of the cases. All patients were also inquired about poor hygienic conditions, atrophic rhinitis, leprosy of nose, chronic rhinosinusitis, chronic granul omatous diseases and malignancy of nose and paranasal sinus. Preoperatively routine investigations like $\mathrm{Hb}, \mathrm{BT}, \mathrm{CT}$, blood sugar, blood urea, ECG, complete urine examination and $X$-ray paranasal sinuses occipitomental view were carried out. Three to 6 hours fasting was ensured before endoscopy and informed consent was obtained in writing. The patients were randomly assigned to two groups using a periodic random number. Group 1 patients were treated by endoscopic removal and group 2 by conventional method.

All patients were operated under local anesthesia after xylocaine sensitivity. Premedication with pentazocine $30 \mathrm{mg}$, promethazine $25 \mathrm{mg}$ and atropine $0.4 \mathrm{mg}$ intramuscular was given half an hour prior to operative procedure. $\mathrm{N}$ asal cavity was anesthetized with cottonoids soacked in $4 \%$ lignocaine with xylometazoline $\mathrm{HCl} 0.1 \%$ for about 15 to 20 minutes. Patient was made to lie down in supine position with head end elevated 10 to $15^{\circ}$ to reduce the venous pressure. External aspect of nose was cleaned and draped. Head was 
Endoscopic Management of Nasal Myiasis: A 10 Years Experience

tilted toward the surgeon. Nasal cavity was infiltered with $2 \%$ xylocaine with adrenaline (1: 200,000). Hopkins rigid nasal endoscope introduced and the larvae which were buried in necrotic material were identified due to their crawling movements and removed one by one by grasping with B lakesley's endoscopy straight or curved forceps (Fig. 1). Complete clearance of nasal cavity was done from choana to anterior nares. After 24 hours same procedure was repeated and clearance of maggots as well as necrotic material was performed.

Postoperatively ciprofloxacin $750 \mathrm{mg} \mathrm{BID}$, levocetrizine $5 \mathrm{mg}$ and tablet diclofenac $50 \mathrm{mg}$ TDS was given for 10 days. Patient was discharged on the next day and advised to clear off debris by nasal douhing with one glass of water fortified with one teaspoonful of sodium bicarbonate $\left(\mathrm{NaHCO}_{3}\right)$ and one pinch of common salts $(\mathrm{NaCl})$ and local instillation of liquid paraffin in each nostril. At the end of 1 week follow endoscopic examination was carried out and dead maggots if any were removed. The control group was treated with local instillation of turpentine oil and intermittently maggots were picked up manual ly from nasal cavity with the help of nasal speculum and Tilley's forceps in 5 to 7 sittings. Postoperative treatment was similar to group 1.

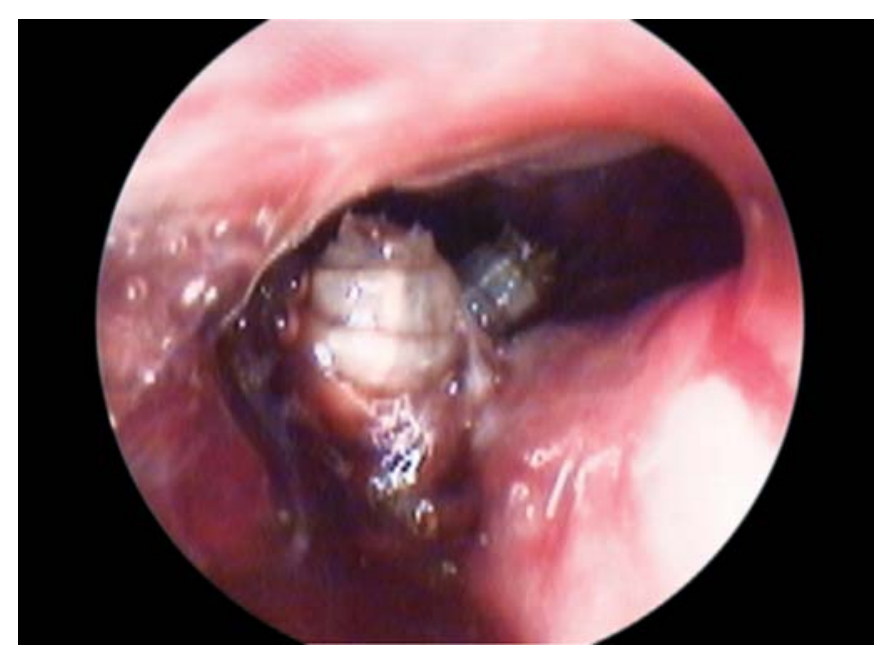

Fig. 1: Endoscopic intranasal view of maggots

\section{RESULTS}

The mean age in study group was 58.6 years (range: 40-60) and in control group it was 56.4 (range: 40-60). In study group of of 72 cases there were $18(25 \%)$ males $54(75 \%)$ females, whereas in control group there were $22(30.5 \%)$ males and $50(69.5 \%)$ females (Table 1$)$.

Mean duration of nasal symptom in study group was 2 days, 24 being on left, 26 on right side and 12 bilateral, in control group it was also 2 days, 20 being on left, 42 on right side and 10 bilateral. M ost of the patients (130) were suffering from atrophic rhinitis which is not uncommon in India, whereas 12 have rhinosinusitis and two had carcinoma.

\begin{tabular}{|c|c|c|c|c|c|}
\hline \multirow[t]{2}{*}{ Group } & \multirow[t]{2}{*}{ Number } & \multicolumn{2}{|c|}{ Age (in years) } & \multicolumn{2}{|c|}{ Sex } \\
\hline & & Mean & $\overline{\text { Range }}$ & Male & Female \\
\hline $\begin{array}{l}\text { 1. Study } \\
\text { 2 Control }\end{array}$ & $\begin{array}{l}72 \\
72 \\
\end{array}$ & $\begin{array}{l}58.6 \\
56.4\end{array}$ & $\begin{array}{l}40-60 \\
40-60\end{array}$ & $\begin{array}{l}18(25 \%) \\
22(30.5 \%)\end{array}$ & $\begin{array}{l}54(75 \%) \\
50(69.5 \%\end{array}$ \\
\hline
\end{tabular}

Endoscopically technique (study group) the mean numbers of removed maggots was 120 (range: 90-160), whereas in conventional technique (control) it was 80 (range: 40-90) at first sitting. The mean duration of endoscopic treatment was 2 days, whereas in control it was 5 days. The difference in mean values of two samples was statistically significant between treatment period ( 2 vs 5 days) and numbers of removed maggots (120 vs 180) in first sitting $(p<0.001)$.

\section{DISCUSSION}

Femal eflies are attracted to odoriferous suppurating lesions, the eggs are deposited on the surface, soft skin or mucosa of various parts of the body that are contaminated by blood or mucus discharge. ${ }^{1}$ These eggs can be transferred to other site by patient's own fingers due to poor hygienic habits and itching. On hatching, the maggots penetrate deep into the tissue aided by their sharp oral hooks and anchoring intersegmental spines which scrape away the tissue and lacerate the fine blood vessels, while feeding. During feeding on necrotic or living tissue the caudal ends of the maggots with their blackish peritremes remains visible at the surface of the lesion, enabling the larvae to breathe. ${ }^{3}$ This visible caudal end of maggots was easily visualized and grasped during endoscopic, hence more maggots could be removed in first sitting especially.

Infestation is commonly implicated to larvae of Chrysomya bezziana, a cause of obligatory myiasis among human and animals in the nose, ear, face, gums and serous cavities. ${ }^{5}$ The predisposing factors include poor hygienic condition, specially with underlying diseases like atrophic rhinitis, leprosy, diabetes with purulent sinus disease, midline granul oma, malignancy and syphilis involving nose as was observed in the present study also. ${ }^{1,6}$ Progressive necrosis of tissue continues which is associated with larval growth and invasion until a large cavernous lesion is formed, where the larvae aggregate and remain active. Hemorrhage from the lesion may be severe and surrounding tissue becomes tense, edematous and emits characteristic pungent odor. Some myiasis cause severe pain, however, carcinomatous lesion or radiotherapy induced radionecrosis destroy sensory nerve endings which may further be destroyed by maggots during the process of invasion, hence there may be no pain. ${ }^{7}$

In our study the mean age was 56.4 and 58.6 years in two groups from rural background and poor low hygienic 
status in control as well as study group. In old age some degree of sensory loss of nasal mucosa may occur, which facilitating flies to lay eggs. In the month of A ugust to October there is hot and humid environmental conditions and this age group sleep either in street or in the fiel ds where the flies gets opportunity to enter in nasal cavity to complete their reproductive cycle. In one sitting one fly lays 200 eggs at a time which hatch in larvae within 24 hours. ${ }^{8}$ However, lower number is due to incomplete hatching or expulsion through nose by sneezing consequent to itching. ${ }^{9}$

Mean duration of nasal symptom in both groups was 2 days. The process of conversion of eggs into larvae takes 24 hours and tissue destruction and symptoms start later on, ${ }^{8}$ hence time of presentation was same in both the groups. Right nostril was affected more than left, may be due to tendency to sleep in right lateral position or putting the finger in right side in the right handed population. Single fly can not lay eggs in two nostrils, however, migration of maggots in other nostril through choanae can occur or may be transported by finger.

Sood et $\mathrm{l}^{5}$ reported that the larvae release toxins to destroy the host tissue. Proteolytic enzymes released by the surrounding bacteria decompose the tissue and the larvae feed on this rotten tissue. The infected tissue frequently releases foul smelling discharge. As the interaction of toxin or enzyme released by the larvae-bacteria can also cause bony erosion of skull base structures which may cause meningitis. Treatment comprises systemic and local measures. Systemic treatment includes broad-spectrum antibiotics, such as ampicillin and amoxycillin especially when the wound is secondarily infected. Topical treatment consists of application of turpentine oil, mineral oil, ether, chloroform, ethyl chloride, mercuric chloride, creosote, saline, systemic butazolidine or thiabendazole for removal of the larvae. ${ }^{2,5,6}$

The larvae are photophobic and prefer to hide in deepest part of nasal cavity even in Eustachian tube. ${ }^{10}$ In control group local application of turpentine oil is effective in killing the maggots which were removed with forceps, however, some larvae get suffocated and come out of the nasal cavity. A ll maggots can not be removed in single stage as the larvae try to hide in deeper site, hence complete clearance requires many sittings. ${ }^{7,8}$

$N$ asal endoscopy is performed to remove crawling maggots by picking up with endoscopic forceps under direct vision from cavernous cavity to shorten the duration of treatment. Soni ${ }^{4}$ reported that larvae cause extensive necrosis, sloughing and destruction of intranasal tissue and reach to deep and inaccessible areas of the nose and paranasal sinuses. In such a situation removal of maggots is difficult by manual extraction and several sittings are required. M eticulous clearing of debris in postoperative period is necessary for good results which can easily be achieved by endoscopy. ${ }^{11,12}$

In comparing both methods nasal endoscopic procedure was found to be superior to the manual extraction method for removal of maggots. The disease was controlled in shorter time, i.e. in couple of sittings. Thus, quick and complete eradication of myiasis is possible before the maggots cause irreparable damage to the intranasal tissues.

\section{REFERENCES}

1. M anfrim AM, Cury A, Demeneghi P, Jotz G, Roithmann R. $N$ asal myiasis: Case report and literature review. Int Arch Otorhinolaryngol 2007;11:74-79.

2. A mreliwala M S, Jain SK T, R aizada R M , Chaturvedi V N. Nasal myiasis. Indian J Otolaryngol Head N eck Surg 1996;48:25-28.

3. A rora S, Sharma JK, Pippal SK, Sethi Y, Y adav A. Clinical etiology of myiasisin ENT: A reterograde period: Interval study. B raz J Otorhinolaryngol 2009;75:356-61.

4. Soni NK. Endoscopy in nasal myiasis. T rop Doct 2000;30:225-27.

5. Sood V P, K akkar PK, W attal BL, M yiasis in otorhinolaryngology with entomological aspects. J Laryngol Otol 1976;90:393-99.

6. Singh I, Gathwala G, Y adav SPS, Wig U, Jakhar KK. M yiasis in children: The Indian perspective. IntJ Pediatr Otorhinolaryngol 1993;25:127-31.

7. Gopalakrishnan S, Srinivasan R, Saxena SK, Shanmugapriya J. $M$ yiasis in different types of carcinoma cases in Southern India. Indian J Med M icrobiol 2008;26:189-92.

8. Sinha V, Sidhartha S, N inama M, Gupta D, Prajapati B, M ore Y. Nasal myiasis. J Rhinol 2006;13:120-23.

9. Gupta SC. Permanent closure of the nostrils in recurrent nasal myiasis. J Laryngol Otol 1978;92:627-28.

10. Sharma H, Dayal D, A grawal SP. Nasal myiasis: Review of 10 years experience. J Laryngol Otol 1989;103:489-91.

11. Badia L, L und V J. V ile bodies: A n endoscopic approach to nasal myiasis. J Laryngol Otol 1994;108:133-35.

12. T sang WS, Lee DL. N asal myiasis: The role of endoscopy. Ear Nose Throat J 2009;88:1250-51.

\section{ABOUT THE AUTHORS}

\section{Rupender K Ranga (Corresponding Author)}

Director, Department of O tolaryngology, B harat ENT and Endoscopy Hospital, Rohtak Gate B hiwani-127021, Haryana, India, e-mail: bharatentbwn@sify.com rupenderent@yahoo.co.in

\section{SPS Yadav}

Senior Professor, D epartment of O tolaryngology, Pt. BD Sharma Post Graduate Institute of M edical Sciences, Rohtak, Haryana, India

\section{Anuj Goyal}

A ssistant Professor, Department of Otolaryngology, Saraswathi Institute of M edical Sciences, Hapur, U ttar Pradesh, India

\section{Arpit Agrawal}

Resident, Department of Otorhinolaryngology, Pt. BD Sharma Post Graduate Institute of M edical Sciences, R ohtak, Haryana, India 